\title{
A Review on the Pharmacological Activity of Local Grown Indian Plants
}

\section{Savita Dixit ${ }^{1 *}$ and Nipun Mohindra ${ }^{2}$}

${ }^{1}$ Professor and Head, Department of Chemistry, Maulana Azad National Institute of Technology, Bhopal, MP, India

${ }^{2}$ B.tech Chemical Engineering, University of Petroleum and Energy Studies, Dehradun

*Corresponding Author: Savita Dixit, Professor and Head, Department of Chemistry, Maulana Azad National Institute of Technology, Bhopal, MP, India.

Received: June 18, 2019; Published: July 11, 2019

DOI: $10.31080 /$ ASNH.2019.03.0366

\begin{abstract}
Since primitive times a number of plants have been utilized for the treatment of various serious ailments as is recorded in Ayurveda. The main aim of using these plants are to maintain health and cure ailments. The key role in this direction is that of oxidative stress. It is the main felon in pathogenesis and pathophysiology of various human diseases. Plants are rich sources of phytochemicals and possess various therapeutic properties. At present compounds which are pharmacologically active are in great demand and if they are from plants they have their set of advantages. In the present study six plants (punica granatum, citrus limon, curcuma longa, wheatgrass, dalbergia sissoo and carica papaya) are viewed for their morphology, phytochemical and pharmacological aspects. These plants are rich sources of phytochemicals and pharmacological activities which supports their traditional uses.
\end{abstract}

Keywords: ROS; Free Radicals; Phytochemicals; Pharmacological Activities

\section{Introduction}

Reactive oxygen species (ROS) or free radicals are continuously produced in all aerobic lives. These are formed naturally within the body as a response to stress and damage the cell membranes. On the other hand, free radicals are mainly produced due to exposure to smoking, chewing tobacco, excessive exposure to sunlight and heavy metals [1].

Antioxidants are the components which neutralizes the effects of the free radicals. In human body oxidants and anti oxidate ratio will be maintained, any alteration in these oxidants and antioxidate will causes accumulation of ROS within the body, this process is called as oxidative stress. Oxidative stress has important role in developing pathological conditions. The human body has an ingrained mechanism for protection against free radicals and ROS called as antioxidant stress. It is defined as a "persistent imbalance between antioxidants and pro-oxidants in favor of the latter, resulting in irreversible cellular damage". They act by scavenging them, suppressing their formation or opposing their action [2].
Presently all over world traditional medicines are being revaluated by research on different plant species and their pharmacological effects. Also, there has been a paradigm shift towards therapeutic evaluation of herbal products in oxidative stress diseases by carefully synergizing the strengths of the traditional systems of medicine with that of the modern concept of evidence-based medicinal evaluation, standardization of herbal products and randomized placebo controlled clinical trials to support clinical efficacy. In the present review six plants (Punica granatum, Citrus limon, Dalbergia sissoo, Carica papaya, Curcuma longa and Wheatgrass) are viewed in detail for their morphological, phytochemical, and pharmacological aspects.

Plants with their pharmacological activities

Punica granatum

Botanical Classification

Kingdom: Plantae, Subkingdom: Tracheobionta

Division: Magnoliophyta, Class: Magnoliopsida

Subclass: Rosidae, Order: Myrtales

Family: Punicaceae, Genus: Punica L.

Species: Punica granatum L. 




Figure 1

\section{Morphology}

The plant of Punica granatum is a deciduous shrub. It grows between 5-8 $\mathrm{m}$ tall. It has multiple spiny branches and is extremely long lived. The leaves of this plant are opposite or subopposite, glossy, narrow oblong. These are 3-7 $\mathrm{cm}$ long and $2 \mathrm{~cm}$ broad. The flowers are bright red and $3 \mathrm{~cm}$ in diameter having 3-7 petals.

The fruit is red purple in color. The fruit mainly consists of two parts i.e an outer hard is the pericarp and the inner spongy mesocarp. This consists of fruit inner wall where arils attach. Thee mesocarp membranes are organized and are non-symmetrical chambers containing seeds inside arils. These contains juice. The seeds in pomegranate ranges from 200-1400.

The berry containing seeds is the edible part. The fruits are the intermediate size of lemon and a grapefruit. The size ranges from $5-12 \mathrm{~cm}$ in diameter with a rounded shape and thick husk. Fruits are rich in polyphenols. The pigmentation of pomegranate juice is due to the presence of anthocyanins and ellagitannins.

\section{Pharmacology and phytochemistry}

Antioxidant activity

- Pomegranates have abundant antioxidant activity due to the presence of flavonoids, flavones, anthocyanins and catechins in different parts of the fruits, seeds and peels. Various experiments have showed that peels and seeds have high antioxidant potential. Methanolic extracts of the peel have shown the highest antioxidant activity among various other extracts tested [3].

- The antioxidant activity of the peel powder and whey powder were evaluated and showed that peel powder has more antioxidant activity [4].

- Various previous reports have proved that leaf and peel exhibited strong antioxidant properties [5].

\section{Antimicrobial effect}

The methanolic extract of peels are a potent inhibitor for Listeria monocytogenes, S. aureus, Escherichia coli and Yersinia enterocolitica [6]. Earlier investigators demonstrated that tannin from the pericarp is a very effective constituent against genital herpes virus (HSV-2) and effectively kills virus and block its absorption to cells [7]. Antifungal activities of pomegranate peel extract, seed extract, juice and whole fruit evaluated. Results confirmed that among the selected bacterial and fungal cultures, the highest antibacterial activity was noticed against Staphylococcus aureus and among fungi high activity was observed against Aspergillus niger [8].

\section{Anaemia}

An experiment was conducted to examine the examine the effects of pomegranate juice (PJ) supplementation on complete blood count (CBC). The results showed that PJ intake for a short period of time may result in increased erythropoiesis or decreased degradation without any significant alterations in factors associated with metabolic health and inflammation in healthy individuals [9].

\section{Active constituents}

Punica granatum is found to contain hydrolysable tannins as major active chemical constituents namely punicalagin, punicalin, gallic acid, ellagic acid and ellagic acid derivative such as ellagic acid, 3, 3'-di-0 -methyl, ellagic acid, 3, 3', 4'-tri-0 -methyl, ellagic acid, 3'- 0 -methyl-3, 4-methylene; phenolic compounds such as pedunculagin, punicacortein $\mathrm{A}-\mathrm{D}$, granatin $\mathrm{A}$ and $\mathrm{B}$, punicafolin, punigluconin, corilagin [10].
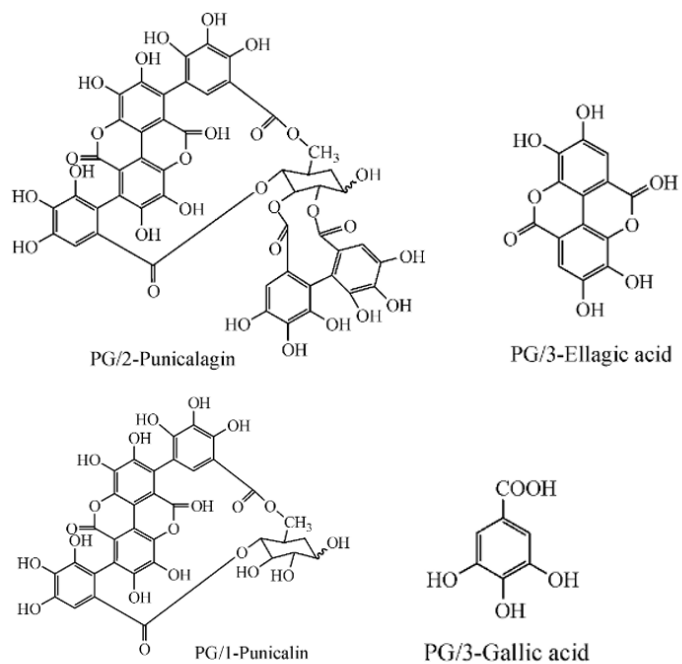

$\mathrm{PG} / 3$-Ellagic acid<smiles>O=C(O)c1cc(O)c(O)c(O)c1</smiles>

PG/3-Gallic acid

Figure 2

Citation: Savita Dixit and Nipun Mohindra. "A Review on the Pharmacological Activity of Local Grown Indian Plants". Acta Scientific Nutritional Health 3.8 (2019): 51-60. 
Following Phenolic compounds are found in the peel extracts of punica granatum [11].


Figure 3

\section{Carica Papaya}

Botanical Classification

Kingdom: Plantae, Subkingdom: Tracheobionta

Superdivision: Spermatophyta, Division: Magnoliophyta

Class: Magnoliopsida, Subclass: Dilleniidae

Order: Violales, Family: Caricaceae

Genus: Carica L., Species: Carica papaya L.

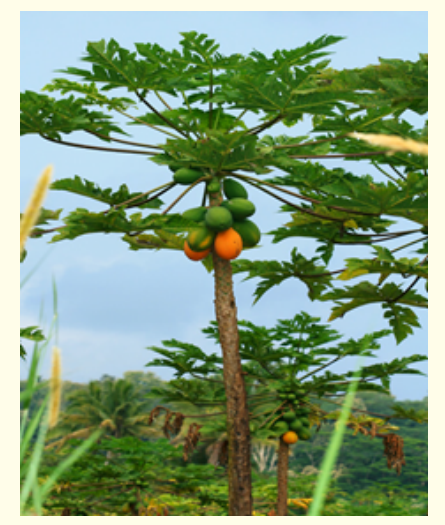

Figure 4

\section{Plant description}

The height of the plant is 20 feet. The flowers emerge from the leaf axils and have 5 white, fleshy, waxy lobes. The plants are sexually variable and can be dioecious (male and female flowers on separate plants), monoecious (male and female flowers on the same plant), or hermaphroditic (having bisexual or "perfect" flowers). The female and hermaphrodite flowers are followed by anywhere from 2 to 20 inch (5 to $50 \mathrm{~cm}$ ) long, round, pear-shaped, or clubshaped, green ripening to yellow, orange, or red-tinged, melon-like fruits with yellow, orange, or salmon-colored flesh and a cavity containing a gelatinous mass of black seeds. The leaves have long, hollow petioles (stalks) and are green, clustered at the stem tips, and deeply palmately lobed with 5 to 9 main lobes that are themselves pinnately lobed. The main stem is slender, upright, and marked with conspicuous leaf base scars. The stems on young plants are green and dark purple, while those of older plants are brown and woody. The foliage and the unripe fruits will ooze milky white latex if cut [12].

\section{Pharmacology and phytochemisry Antioxidant activity}

Carica papaya leaf water extract is effective against gastric ulcer and oxidative stress. The papaya leaf extracts exhibit antioxidant effect by reducing the oxidative damage and boosting the activ-

Citation: Savita Dixit and Nipun Mohindra. "A Review on the Pharmacological Activity of Local Grown Indian Plants". Acta Scientific Nutritional Health 3.8 
ity of endogenous antioxidant glutathione peroxidase. The active components in papaya leaf extract namely papain, ascorbic acid, flavonoids, chymopapain, cyanogenic glucosides, cystatin, and glucosinolates were found to increase the total antioxidant power in the blood and reduce the oxidative damage [13].

\section{Dengue fever}

Commencing on studies of Dr. Sanath Hettige, who conducted the research on 70 dengue fever patients; said papaya leaf juice helps increase white blood cells and platelets, normalizes clotting, and repairs the liver [14].

\section{Immunomodulatory effects}

The research showed the significant growth inhibitory activity of the CP extract on tumor cell lines. In PBMC, the production of IL-2 and IL-4 was reduced following the addition of CP extract, whereas that of IL-12p40, IL-12p70, IFN-gamma and TNF-alpha was enhanced without growth inhibition. In addition, cytotoxicity of activated PBMC against K562 was enhanced by the addition of $\mathrm{CP}$ extract. Moreover, microarray analyses showed that the expression of 23 immunomodulatory genes, classified by gene ontology analysis, was enhanced by the addition of $\mathrm{CP}$ extract. In this regard, CCL2, CCL7, CCL8 and SERPINB2 were representative of these upregulated genes, and thus may serve as index markers of the immunomodulatory effects of CP extract. Finally, it was identified that the active components of $\mathrm{CP}$ extract, which inhibits tumor cell growth and stimulates anti-tumor effects, to be the fraction with M.W. less than 1000 [15].

\section{Active constituents}

In reference to the phytochemical analysis of Carica papaya L., Caricaceae, leaf extract, the presence of flavonoids, tannins, alkaloids and organic acids in a methanolic extract has been previously documented. The main compounds contained by $C$. papaya leaves are phenolic acids, as well as trace amounts of chlorogenic acid, compared to flavonoids and coumarin compounds. It is further suggested that the presence of phenolic and coumarin compounds in C. papaya leaves could partially explain the pharmacological properties of this plant. Different bioactive phytochemicals found in C. papaya possess a wide range of biological activities that can be of valuable therapeutic index [16].

\section{Wheatgrass}

Botanical Classification

Kingdom: Plantae, Subkingdom: Tracheobionta

Superdivision: Spermatophyta, Division: Magnoliophyta

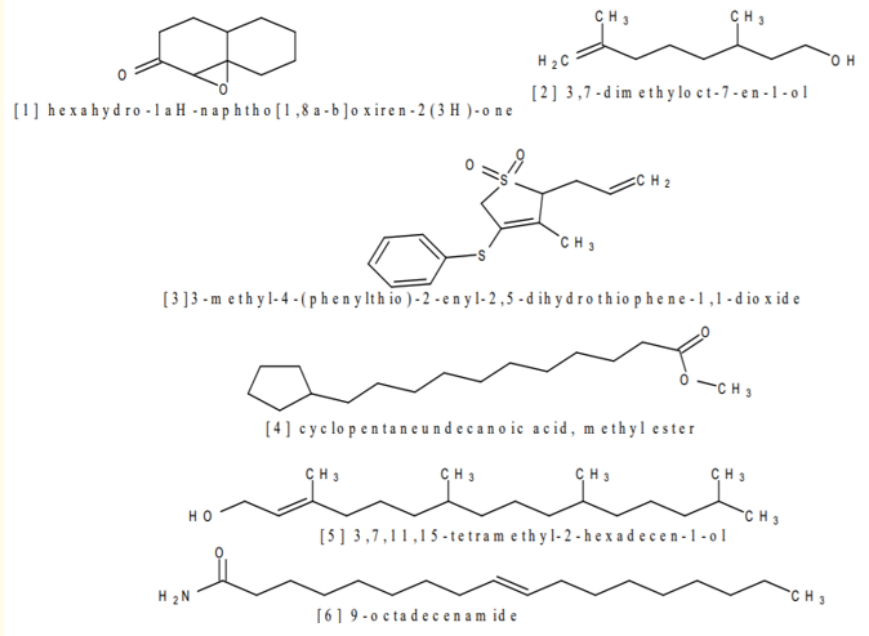

Figure 5

Class: Liliopsida, Subclass: Commelinidae

Order: Cyperales, Family: Poaceae

Genus: Triticum L., Species: Triticum aestivum L.

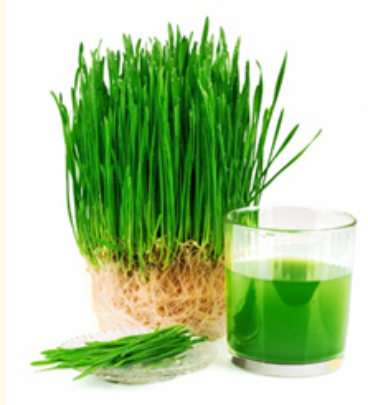

Figure 6

\section{Plant description}

Wheatgrass is young grass shoots of wheat berry. In appearance, wheatgrass is like any other grass. Culms are simple, hollow or pithy, glabrous, $1.2 \mathrm{~m}$ tall. Leaves flat, narrow, 20-38 cm long, $1.3 \mathrm{~cm}$ broad. Spikes long, slender, dorsally, compressed, somewhat flattened; rachis tough, not separating from spikelet's; 2-5 flowered, relatively far apart from stem, slightly overlapping, nearly erect, pressed closed to rachis; glumes keeled in upper half, firm, glabrous, shorter than lemmas; lemmas awned or awnless, less than $1.3 \mathrm{~cm}$ long; palea as long as lemma, remaining entire at maturity, caryopsis free threshing, soft or hard, red or white (hexaploid) [17]. 
Pharmacology and phytochemistry

- Enhances the production of red blood cells: Wheatgrass juice has been proven to build red blood cells quickly after ingestion and has potential to lower transfusion requirement in thalassemiacs. The grass is loaded with vitamin B-12, folic acid and iron, all vital for production of healthy red blood cells.

- Enhances immunity: A strong immune system is of paramount importance in preventing deadly diseases like cancer. The rich array of nutrients in wheatgrass juice and powder helps in strengthening the immune system and keeps the body in perfect health [18].

- Possess anti-oxidant property and fights cancer: The antioxidant-rich phyto nutrients beta-carotene, bioflavonoid, vitamins $\mathrm{B}, \mathrm{C}$ and $\mathrm{E}$ give a tough fight to the free radicals. The anti-oxidant punch in the juice neutralizes adverse effects of free radicals and prevents damage to the DNA and cell structure. Its ability to detoxify the body, prevent DNA damage, boost immunity levels and enhance the production of red blood cells helps fight away carcinogens. Chlorophyll is the active ingredient in the grass that inhibits the metabolic activity of carcinogens [19].

- Detoxifier: Recent studies show that wheatgrass juice has a powerful ability to fight tumors without the usual toxicity of drugs that also exhibit cell destroying agents. The many active compounds found in grass juice cleanse the blood and neutralize and digest toxins in our cells [20].

- In recent years, phytochemicals previously with unknown pharmacological activities have been extensively investigated, as a source one of the medicinal agents. Green Blood Therapy is the use of Wheat Grass Juice (WGJ) to cure multiple diseases. Wheat grass is called as the green blood. The name "green blood" of wheat grass is attributable to its high chlorophyll content which accounts for about $70 \%$ of its total chemical constituents [21].

- Chelating activity: The wheat grass extracts quench the formation of ferrozine $-\mathrm{Fe}^{2+}$ complex. The protective effects of wheat grass towards the erythrocyte membranes can be attributed to their iron chelating capacities, since they can extract iron ions and hinder radical reactions. Moreover, the phenolic and flavonoid compounds can scavenge free hydroxyl and peroxy radicals and protect the membranes. The phenolic compounds stabilize the erythrocyte membrane by interaction with the membrane phospholipids [22].
- Wheat grass is used for swelling on the joints, pain in the joints, osteoarthritis, bone rotting. The ability of wheatgrass in the maitainence of bone and joint diseses is due to its strong anti-inflammatory effect. It can significantly assist to lower pain, swelling and inflammation, and stop subcutaneous and cutaneous bleeding rapidly, therefore increasing the natural healing process [23].

- Active Constituents: Following are the compounds isolated from the aqueous extracts of Triticum aestivum [24].

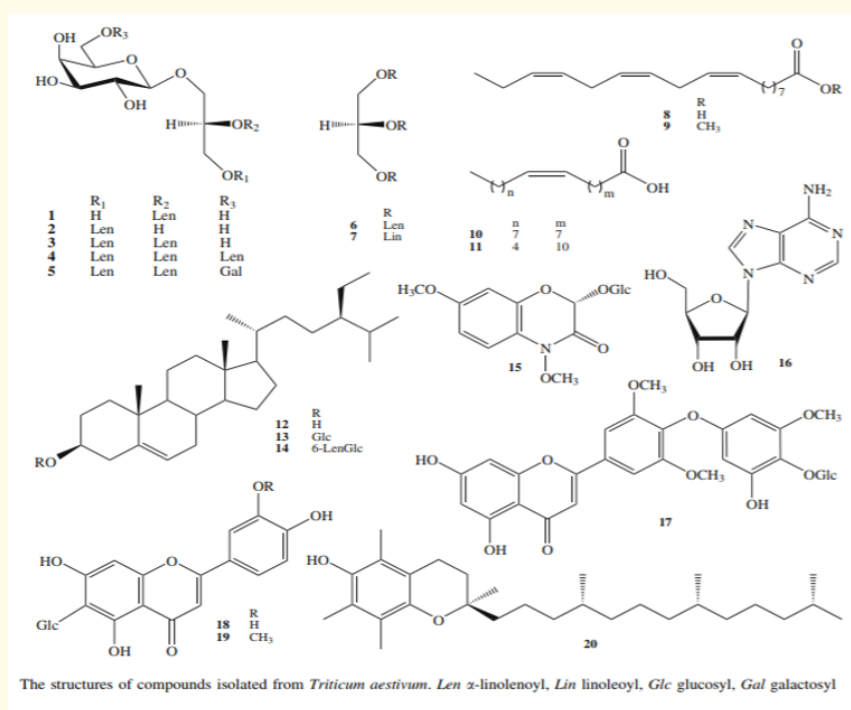

Figure 7

\section{Curcuma longa}

Botanical Classification

Kingdom: Plantae, Subkingdom: Tracheobionta

Superdivision: Spermatophyta, cDivision: Magnoliophyta

Class: Liliopsida, Subclass: Zingiberidae

Order: Zingiberales, Family: Zingiberaceae

Genus: Curcuma L., Species: Curcuma longa L.

\section{Plant description}

This is a herb with branched rhizome, bright orange inside and outside. The young tips are white. The leaf sheaths are up to $65 \mathrm{~cm}$ long. Its blades are oblong-lanceolate to egg-shaped-lance-shaped, 7-70 cm x 3-20 cm in size, densely studded with pellucid dots. The inflorescence is terminal, perched on a leafy shoot. The bracts are pale green with white streaks or white margins. The coma bracts are white but sometimes pink-tipped. The petal is $4.5-5.5 \mathrm{~cm}$ long and white. The labellum is suborbicular to obovate. It is $12-22 \mathrm{~mm}$ 


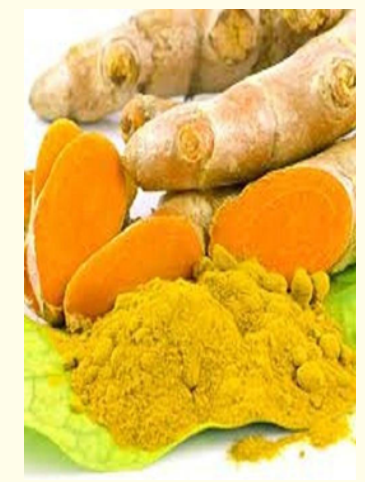

Figure 8

in diametre, white with a yellow median band. The other staminodes are longitudinally folded, creamy white and the anther has large spurs [25].

\section{Pharmacology and phytochemistry}

- Anti-inflammatory activity: There is a great number of papers in the literature relating the activity of compounds extracted from $C$. longa $\mathrm{L}$. being potent inhibitors of inflammation. These substances can be classified as curcuminoids, analogues of diarylheptanoids [26]

- Turmeric leaves contain antioxidants, as well as organic compounds such as a-Pellandrene. which gives eucalyptus its minty aroma, and terpinolene, which is also found in allspice. They also contain the compound 8-cineole, which has therapeutic properties as an antispasmodic, antiviral, analgesic and anti-inflammatory [27].

- Boosts Digestion: Crushed turmeric or haldi leaves can help boost digestion and reduce problems of gas and bloating. Curcumin is said to trigger bile production, which is one of the main components of digestion. Increased secretion of bile juice aids smoother digestion [28].

- Turmeric leaf is beneficial for the liver. The extract of the leaves and rhizome can increase bile flow and offer protection for gallbladder.

- The leaf extracts have anti-cancer properties. Significant amount of the spice has shown to inhibit division of leukaemia cells in children

- Active Constituents: Following are the chemical compounds extracted from the methanolic extracts of $C$. longa rhizome methanolic extract.

\section{Citrus Limonum}

Botanical Classification

Kingdom: Plantae, Subkingdom: Tracheobionta

Superdivision: Spermatophyta, Division: Magnoliophyta

Class: Magnoliopsida, Subclass: Rosidae

Order: Sapindales, Family: Rutaceae

Genus: Citrus L., Species: Citrus limonum L.

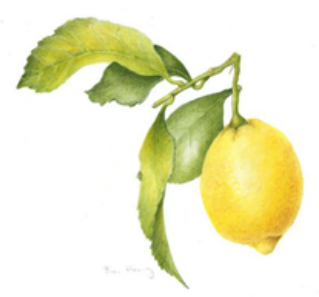

Figure 10 


\section{Plant description}

The true lemon tree reaches 10 to $20 \mathrm{ft}$ (3-6 m) in height and usually has sharp thorns on the twigs. The alternate leaves, reddish when young, become dark-green above, light-green below; are oblong, elliptic or long-ovate, $21 / 2$ to $41 / 2$ in $66.25-11.25$ $\mathrm{cm}$ ) long, finely toothed, with slender wings on the petioles. The mildly fragrant flowers may be solitary or there may be 2 or more clustered in the leaf axils. Buds are reddish; the opened flowers have 4 or 5 petals $3 / 4$ in $(2 \mathrm{~cm})$ long, white on the upper surface (inside), purplish beneath (outside), and 20-40 more or less united stamens with yellow anthers. The fruit is oval with a nipple-like protuberance at the apex; $23 / 4$ to $43 / 4$ in $(7-12 \mathrm{~cm}$ ) long; the peel is usually light-yellow though some lemons are variegated with longitudinal stripes of green and yellow or white; it is aromatic, dotted with oil glands; $1 / 4$ to $3 / 8$ in (6-10 mm) thick; pulp is pale-yellow, in 8 to 10 segments, juicy, acid. Some fruits are seedless, most have a few seeds, elliptic or ovate, pointed, smooth, 3/8 in $(9.5 \mathrm{~mm})$ long, white inside [29].

\section{Pharmacology and phytochemistry}

- Lemon peel benefits consists of carminative, stimulant, lemon peel oil is used as perfume, flavoring agent, used for the extraction of pectin and volatile oil [30].

- The peel of Citrus fruit is a rich source of flavanones and many polymethoxylated flavones, which are very rare in other plants [31].

- $\quad$ Natural extracts of Citrus peel are also used in the pharmaceutical industry for medicinal preparation, soaps, perfumes and other cosmetics.

- The citrus peels are rich in nutrients and contain many phytochemicals, these are $\beta$ and $\gamma$-sitosterol, glycosides and volatile oils.

- Some polyethoxylated, phenolic compound, ascorbic acid, flavones have several important activities, which are very rare in other plants.

- Citrus peels also used in scurvy, digestion, respiratory disorders, peptic ulcer, eye infections, gums, gout, skin care, piles, urinary disorders, weight loss traditionally. In addition, it also used in disinfect and sterilizing reagent [32].

- Active Constituents: Following active constituents have been isolated from the essential oils of lemon peel [33,34].
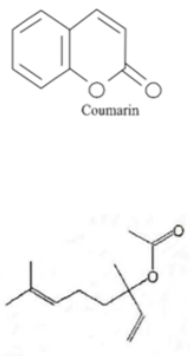

Linalyl acetate
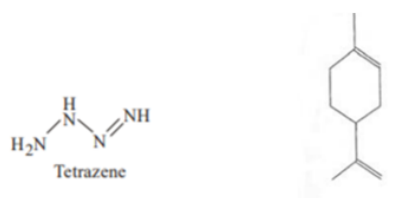

Limonene


B- Pinene
Figure 11

\section{Dalbergia Sissoo}

Botanical Classification

Kingdom: Plantae, Subkingdom: Tracheobionta

Superdivision: Spermatophyta, Division: Magnoliophyta

Class: Magnoliopsida, Subclass: Rosidae

Order: Fabales, Family: Fabacea

Genus: Dalbergia L., Species: Dalbergia Sissoo Roxb.

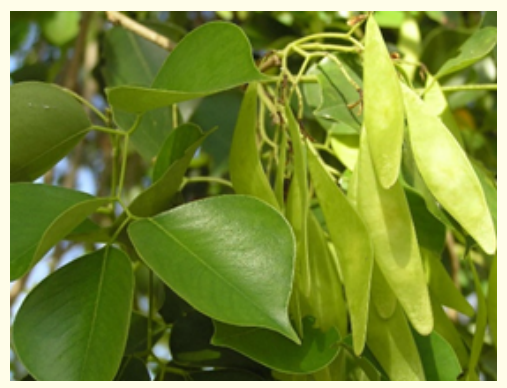

Figure 12

\section{Plant description}

Dalbergia sissoo is a decidious tree with an open spreading crown that reaches a height between 15-35 metres. The trunk is often crooked with thin, grey bark, furrowed and exfoliating in narrow strips as it matures. It has a long taproot and an extensive lateral root system, often at the soil surface and producing suckers. The leaves are alternately arranged, compound and oddly pinnate, with 3-5 glabrous, leathery leaflets, elliptical to ovate, tapering to 
a point and $2.5-3.6 \mathrm{~cm}$ in diameter. Flowers are arranged in axillary panicles, $2.5-3.7 \mathrm{~cm}$ long, inconspicuous, white to dull yellow. Flowers are fragrant with pubescent sepals $4-5 \mathrm{~mm}$ long, and petals $6-8 \mathrm{~mm}$ long. Fruits are indehiscent, $5-7.5 \mathrm{~cm}$ long and $8-13 \mathrm{~mm}$ wide, rounded with minute points, pale brown in colour (PIER, 2006), and persistent on the tree. The seed is kidney-shaped, thin, flat, and light brown with 1-4 seeds in a pod [35].

Pharmacology and phytochemistry

- Its leaf juice is used for eye ailments.

- Wood and bark act as abortifacient, anthelmintic, antipyretic, aphrodisiac, expectorant, and refrigerant also used in anal disorders, blood diseases, burning sensations, dysentery, dyspepsia, leucoderma, skin ailments, blood disorders, burning sensations, eye and nose disorders, scabies, scalding urine, stomach problems, and syphilis, boils, eruptions, leprosy and nausea [36].

- Leaf extract has been used to treat sore throats, heart problems, dysentery, syphilis, and gonorrhea.

- In India and Nepal rural people use Dalbergia sissoo leaves to treat animals suffering from non-specific diarrhoea.

- $\quad$ People use twigs of tree to clean their teeth [37].

- Antioxidant potential: Stem bark of Dalbegia sissoo were evaluated for its antioxidant potential. Finally results shown, among the different extracts of stem bark of the plant, chloroform extract exhibited marked antioxidant activity, whereas methanolic extract shown moderate activity in different in vitro anti-oxidant assays [38].

- Anti-diabetic potential: Pankaj singh Niranjan., et al. conducted a study in 2010 to evaluate the anti-diabetic activity of ethanolic extract of Dalbergia sissoo leaves in alloxan induced diabetic rats. They concluded that the ethanolic extract of the leaves are $12 \%$ more effective in reducing the blood glucose level compared to standard Glibenclamide [39].

- Osteogenic Activity: One new isoflavone glucoside, caviunin 7-0-[ $\beta$-D- apiofuranosyl-( $1 \rightarrow 6)-\beta$-D-glucopyranoside] and a new itaconic derivative, (E)-4-methoxy-2-(3,4dihydroxybenzylidene)-4-oxobutanoic acid along with series of isoflavones and flavonols with their glucosides and a lignan glucoside were isolated from the ethanolic extract of Dalbergia sissoo leaves and were assessed for osteogenic activity in primary calvarial osteoblast cultures. Result showed that compounds exhibited significant osteogenic activity [40].
- Active Constituents: Following compounds have been isolated from the leaves of $D$. Sissoo Leaves [41,42].
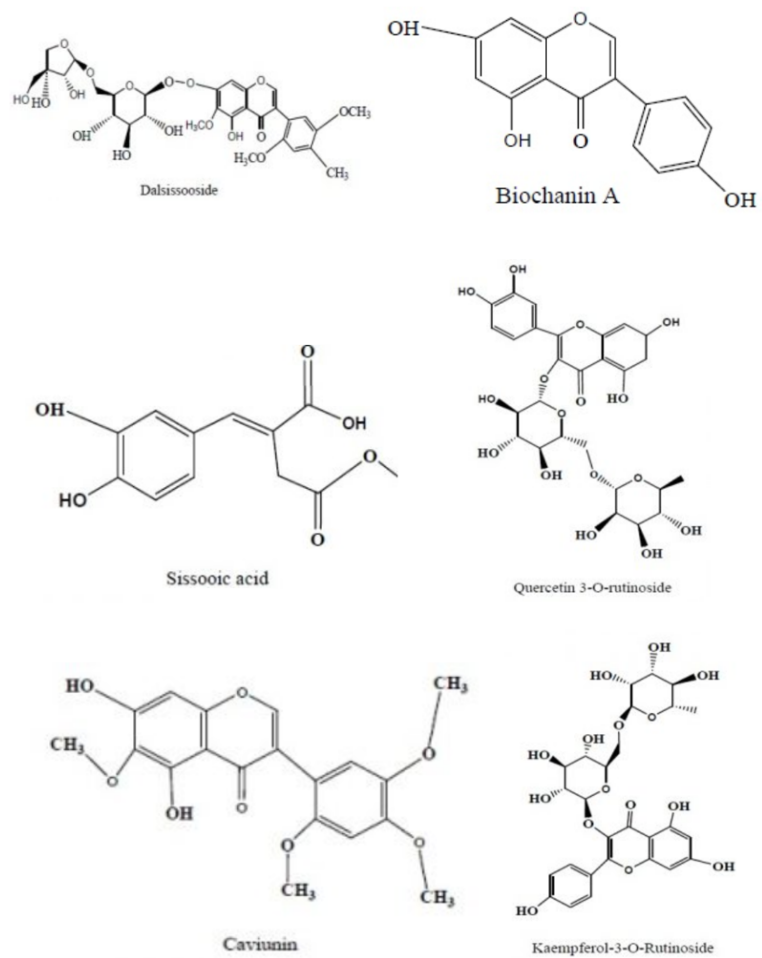

Figure 13

\section{Conclusion}

There are evidences suggesting that free radicals and reactive oxygen species (ROS) can be involved in high number of fatal diseases. Many synthetic antioxidants are being used in processed foods exhibit side effects and are carcinogenic. Various natural antioxidants can be useful in avoiding serious effects due to oxidative stress. This thought has opened various areas of research. Various phytochemicals and antioxidants from plants have attracted interest in them. In the present work P. granatum, C. limon, C. papaya, $C$. longa, wheatgrass and $D$. sissoo have been reviewed for their pharmacological properties. The phytochemical analysis of these plants have revealed a large number of compounds including flavonoids and phenolics which have shown potent antioxidant activity. These compounds have been used as anti-oxidant, ant-carcinogenic, antifungal, antibacterial, anti-spasmodic, anti-inflammatory and antidiabetic. 


\section{Bibliography}

1. Van Wijk R., et al. "Free radicals and low-level photon emission in human pathogenesis: State of the art". Indian Journal of Experimental Biology 46.5 (2008): 273-309.

2. Kiran Kumar Kattappagari., et al. "Role of antioxidants in facilitating the body functions: A review". JOFS 7.2 (2015): 71-75.

3. Singh RP., et al. "Studies on the antioxidant activity of pomegranate (Punica granatum) peel and seed extracts using in vitro models". Journal of agricultural and food chemistry 50.1 (2002): 81-86.

4. Ashoush IS., et al. "Antioxidant activity and hepatoprotective effect of pomegranate peel and whey powders in rats". Annals of Agricultural Sciences 58.1 (2013): 27-32.

5. Sadeghi N., et al. "Antioxidant activity of Iranian pomegranate (Punica granatum L.) seed extracts". Journal of Agricultural Science and Technology 11 (2010): 633-638.

6. Al-Zoreky NS. "Antimicrobial activity of pomegranate (Punica granatum L.) fruit peels". International journal of food microbiology 134.3 (2009): 244-248.

7. Zhang J., et al. "Antiviral activity of tannin from the pericarp of Punica granatum L. against genital Herpes virus in vitro". China journal of Chinese materia medica 20.9 (1995): 556-558.

8. Dahham SS., et al. "Studies on antibacterial and antifungal activity of pomegranate (Punica granatum L.)". American-Eurasian Journal of Agricultural and Environmental Sciences 9.3 (2010): 273-281.

9. Eirini Manthou., et al. "Effect of pomegranate juice consumption on biochemical parameters and complete blood count". Experimental and Therapeutic Medicine 14.2 (2017): 17561762.

10. Vishal Jain., et al. "Isolation and Standardization of Various Phytochemical Constituents from Methanolic Extracts of Fruit Rinds of Punica granatum". Chinese Journal of Natural Medicines 9.6 (2011): 414-420.

11. Amani S Al-Rawahi., et al. "Phenolic Constituents of Pomegranate Peels (Punica granatum L.) Cultivated in Oman". European Journal of Medicinal Plants 4.3 (2014): 315-331.

12. https://wildlifeofhawaii.com/flowers/1522/carica-papayapapaya/
13. Aravind and Debjit. "Traditional and Medicinal Uses of Carica papaya” Journal of 'Medicinal Plants Studies'1.1 (2013): 23203862.

14. Otsuki N. "Aqueous extract of Carica papaya leaves exhibits anti-tumor activity and immunomodulatory effects". Journal of ethnopharmacology 127.3 (2010): 760-767.

15. Rochway. "Benefits of papaya leaf extract" (2013).

16. Isela E Juárez-Rojop., et al. "Phytochemical screening and hypoglycemic activity of Carica papaya leaf in streptozotocin-induced diabetic rats". Revista Brasileira de Farmacognosia 24.3 (2014): 341-347.

17. Shirude Anup Ashok. "Phytochemical and Pharmacological Screening of Wheatgrass Juice (Triticum Aestivum L.)". International Journal of Pharmaceutical Sciences Review and Research, 9.1 (2011): 029

18. Kulkarni S., et al. "Evaluation of the antioxidant activity of wheatgrass (Triticum aestivum L.) as a function of growth under different conditions". Phytotherapy Research 20.3 (2006): 218-227.

19. Bar-Selaa G., et al. "Wheat Grass Juice May Improve Hematological Toxicity Related to Chemotherapy in Breast Cancer Patients: A Pilot Study". Journal Nutrition and Cancer 58.1 (2007): 43-48.

20. http://www.ncbi.nlm.nih.gov/pubmed/16521113

21. "The medicinal properties and value of wheatgrass (Triticum aestivum.L)", Literature Review as part of BSc Applied Biological Science (Plant Science) (2012).

22. Malla S., et al. "Healing effects of Wheat Grass (Triticum aestivum L) extracts on RBC Membrane Damage". American Journal of Life Sciences 2.6-1 (2014): 22-27.

23. Chawla Payal., et al. "Wheat Grass: A Review on Pharmacognosy And Pharmacological Aspects". International Journal of Phytopharmacology 6.2 (2015): 80-85.

24. Bui Thi., et al. "Chemical constituents of Triticum aestivum and their effects on adipogenic differentiation of 3T3-L1 preadipocytes". Archives of Pharmacal Research 38.6 (2015): 10111018. 
25. https://www.britannica.com/plant/turmeric

26. LL Leon., et al. "Biological Activities of Curcuma longa L". Memórias do Instituto Oswaldo Cruz 96.5 (2001): 723-728.

27. http://www.specialtyproduce.com/produce/Turmeric Leaves_11168.php

28. https://food.ndtv.com/food-drinks/5-incredible-benefits-ofturmeric-leaves-you-must-know-1812254

29. Morton, J. Citrus limon. Lemon. In: Fruits of warm climates. Julia F. Morton, Miami, FL. (1987): 160-168.

30. http://www.cricketfundas.com/health-fundas/lemon-peelchemical-constituents-uses-and-synonyms/

31. Saumendu Deb Roy., et al. "Pharmacognostic, phytochemical, physicochemical property and antimicrobial activity studies of lemon peel oil". Journal of Natural Product and Plant Resources 2.3 (2012): 431-435.

32. Junab Ali., et al. "Antimicrobial Activity of Lemon Peel (Citrus Limon) Extract". International Journal of Current Pharmaceutical Research 9.4 (2017): 79-82.

33. Maruti J., et al. "Study Antimicrobial Activity of Lemon (Citrus lemon L.) Peel Extract”. British Journal of Pharmacology and Toxicology 2.3 (2011): 119-122.

34. Djamel Djenane. "Chemical Profile, Antibacterial and Antioxidant Activity of Algerian Citrus Essential Oils and Their Application in Sardina pilchardus". Foods 4.2 (2015): 208-228.

35. Global Invasive Species Database. Species profile: Dalbergia sissoo (2018).

36. Sabira Sultana., et al. "Dalbergia Sissoo Roxb" Monograph". Indian Journal of Pharmacology 2.9 (2015): 440-443.

37. Shah $\mathbf{M H}$., et al. "Medicinal importance and association of pathological constraints with Dalbergia sissoo". Pakistan Journal of Phytopathology 22.2 (2010): 135-138.

38. Kaur A., et al. "Evaluation of antioxidant potential of stem bark extract of Dalbergia sissoo". Journal of Pharmacy Research 4.10 (2011): 3439-3441.

39. Niranjan PS., et al. "Antidiabetic activity of ethanolic extract of Dalbergia sissoo L. leaves in alloxaninduced diabetic rats". International Journal of Current Pharmaceutical Research 2.2 (2010): 24-27.
40. Dixit., et al. "Constituents of Dalbergia sissoo Roxb. leaves with osteogenic activity". Bioorganic and Medicinal Chemistry Letters 22.2 (2012): 890-897.

41. Rohit Kumar Bijauliya., et al. "Dalbergia Sissoo Linn. An Overview Morphology, Phytochemistry And Pharmacology". International Journal of Pharmaceutical Sciences and Research 8.4 (2017): 1522-1533.

42. Chandan Singh., et al. "Biocompatible synthesis of silver and gold nanoparticles using leaf extract of Dalbergia sissoo Published online by the VBRI press in 3.4 (2012): 279- 285.

\section{Volume 3 Issue 8 August 2019 \\ (C) All rights are reserved by Savita Dixit and Nipin}

\section{Mohindra.}

